\title{
Effects of acculturation of assimilation in the search for cultural identity by the Punjabi ethnic minority in Medan, Indonesia by Nuraini 2 Unimed
}

Submission date: 03-Jun-2021 01:05PM (UTC+0700)

Submission ID: 1599485270

File name: dentity_by_the_Punjabi_ethnic_minority_in_Medan_Indonesia_1.pdf (1.1M) Word count: 7020

Character count: 38775 
Effects of acculturation of assimilation in the search for cultural identity by the Punjabi ethnic minority in Medan, Indonesia

Nur'Aini

To cite this article: Nur'Aini (2021): Effects of acculturation 10 assimilation in the search for cultural identity by the Punjabi ethnic minority in Medan, Indonesia, Journal of Human Behavior in the Social Environment, DOI: 10.1080/10911359.2020.1825257

To link to this article: https://doi.org/10.1080/10911359.2020.1825257

Published online: 08 Jan 2021

Submit your article to this journal ๘

View related articles ¿

View Crossmark data 〔 


\section{Effects of acculturation of assimilation in the search for cultural identity by the Punjabi ethnic minority in Medan, Indonesia}

\begin{abstract}
Nur'Aini (D) Indonesia

ABSTRACT

This study examines the effects of acculturation of assimilation in the search for cultural identity by the Punjabi ethnic group in Medan, Indonesia. Punjabi ethnic is a unique and long-standing ethnic minority group that migrated to Indonesia with their Sikh religion and their culture, which is friendly and interesting. Acculturation of assimilation is a predictor that can influence adjustment, and ethnic identity unexamined, search, and achieved as a mediator that supports the formation of adaptation to peers in the educational environment. The subject of this 5 search is Punjabi teenagers. The research used qualitative method to provide added value for identifying and exploring intangible factors such as cultural expectations, gender roles, ethnic and religious implications, and individual feelings. Results show that acculturation of assimilation is mediated by ethnic identity unexamined, search, and achieved as a role in the effort to build adaptation to peers in the educational environment. Consequently,acculturation of assimilation showed adaptability.
\end{abstract}

Department of Education Psychology and Counselling, Faculty of Education Science, Universitas Negeri Medan,

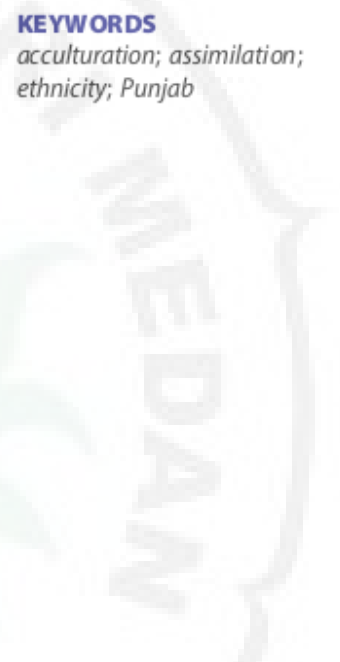

\section{Introduction}

One of the ethnic minority communities residing in Indonesia is the Punjab, a sub-ethnic group from India. The Punjab population is fewer and concentrated in certain areas when compared with other ethnic immigrants like Tiong-Hoa, whose population is mort and widely spread. Punjabis are from the north of India, in genereit today many of them live in the city of Medan, North Sumatra, and Jakarta in particular. Indonesia is one of the largest countries in the world whose population consists of various ethnicities, races, and cultures spread throughout the archipelago. This diversity makes the Indonesian people believe in culture, and at the same time tend to be open 19 immigrants and change (Saleh et al., 2018).

According to Suharyanto and Hidayat (2018) Activities that personally and even privacy, give color to the city of Medan, as a city that does not have a dominant culture. Where the cultural elements of each ethnic group (ethnic group) have diverse and significant characteristics. Ethnic diversity or diversity refers to the existence of many ethnicities where one is not inferior to the other, thus encouraging the strengthening of the identity of each ethnic in the city of Medan. The population of the Punjab community in Medan is +2000 people, and from year to year there is an in ${ }_{1}$ ase (the foundation that houses the Punjab). As many as $90 \%$ of the population of the Punjab community in the city of Medan mix and mingle with people of different cultures/ ethnicities, while another $10 \%$ live in colonies with their ethnic peers (Figure 1).

CONTACT Nuraini mrsnuraini545@gmail.com Universitas Negeri Medan, Medan, 20221, Indonesia

๑ 2020 Taylor \& Francis Group, LLC 


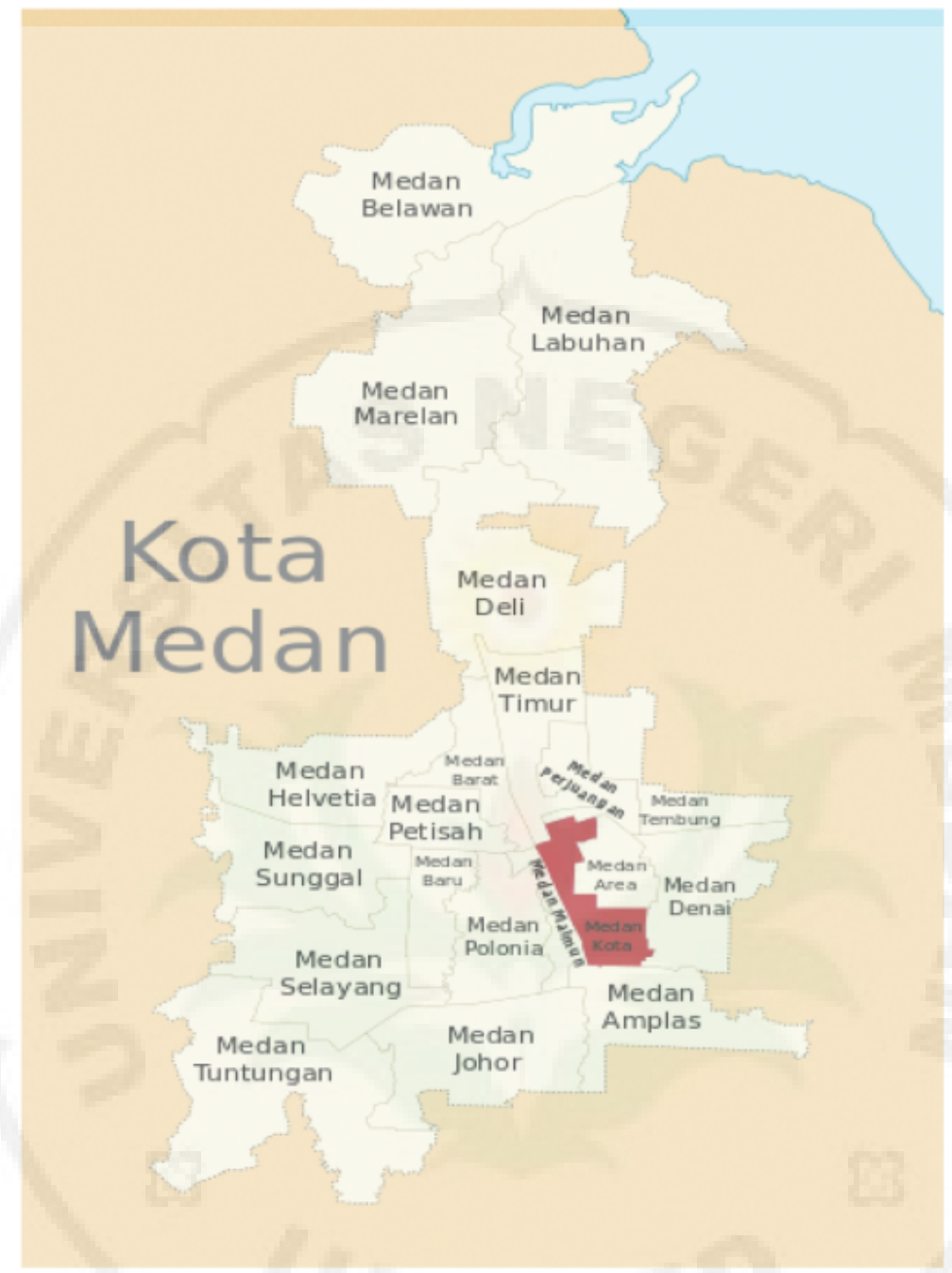

Figure 1. Medan city map.

Even though their religion has not been recognized in Indonesia, Punjabis are very strongly bound to the system of norms and customs, religion, and language. They have their own culture and religion that they brought with them since the da ${ }_{4}$ of their ancestors, and which for generations have characterized their way of life. Though generally they have been integrated with the people in the city of Medan, with a background of diverse cultures, but they are still determined to maintain the prevailing culture within the community, as they use the language of Punjabi and eat traditional foods commonly eaten, religious teachings which require the wearing of turbans, scarves and traditional clothing, customs such as childbirth, marriage, death events, and Punjab tribal days.

With the above characteristics, the Punjab ethnic minorities are often constrained to adapt to the social environment outside their ethnicity, due to the pressure they face in trying to maintain these characteristics in accordance with the culture and religious teachings that they believe in their community. For example, if schools should choose and follow religious lessons other than 
the Sikh religion, if they should require for students to cut their hairs, and put aside clothes that they are supposed to wear daily, which is a prohibition in religious teachings, these conditions will bring about some constraints of social adaptation. On the other hand, if they do not comply, then they will face obstacles in making adjustments in the community such as in their work places, in their interpersonal relationship with others, and in the educational environment. Therefore, many Punjab communities have observed some violations in the teachings of their religion.

\section{Literature review}

\section{Definition of adjustment}

The notion of adjustment is based on the approach used in theory. Adjustment takes place continuously and throughout life according to the level of individual development in facing his environment. Thus, the individual will always make adjustments throughout his lifetime, whether in the 5 mily environment, school, or community. Schneider and Dan Ward (2003), stated that adjustment is a process that involves both mental and behavioral responses, in which an individual seeks to address the inner needs, tensions, frustrations, and conflicts, and to achieve a level of harmony between the inner and objective demands of the environment in which he lives.

From this definition, it can be argued that self-adjustment is a process that encompasses mental and behavioral responses, which is an individual's effort to successfully meet the needs, tensions, conflicts and frustrations experienced within himself. The individual's effort aims to obtain harmony and harmony between the inner demands with what is expected by the environment. Schneider and Dan Ward (2003) $\mathrm{a}_{2} \mathrm{o}$ observed that a welladjusted person is one who, with his own limitations, learns to react to himself and the environment in a mature, useful, efficient, and satisfying way, and can solve conflicts, frustrations, as well as personal and social difficulties without any disruption of behavior.

Kartono (2008), stated that self-adjustment is an attempt to achieve harmony with oneself and the environment, so that hostility, jealousy, envy, prejudice, depression, and anger as inappropriate personal responses can be eroded. While Desmita (2009), stated that self-adjustment is a broad and complex psychological constructs, and involves all individual reactions to the demands, both from the environment and from within the individual himself.

Schneider and Dan Ward (2003), observed that adjustment can be classified based on symptoms and causes, the type of response, and according to the problem. Classification according to the symptoms is appropriate to the person involved, and it is categorized into neurotic, psychotic, psychopathic, evil, eccentric, and epileptic, and according to causes such as organic and psychogenic. The classification according to the type of response can be distinguished as; (1) Normal adjustment, (2) Adjustment by using defense reaction, (3) Adjustment by evasion and withdrawal, (4) adjustment to disease, (5) Adjustment with attack. While the classification based on the situational context of the problem in meeting the demands of self and the environment is grouped as; (1) Personal adjustment, (2) Social adjustment, (3) Adjustment of home and family, (4) Adjustment of academic, (5) Vocational adjustment, (6) Adjustment of marriage. This is supported by the opinion of Baker \& Siryk (1984), that adjustment in the 
educational environment can be done by assessing aspects such as; (1) personalemotional adjustment, (2) social adjustment, (3) academic adjustment, and (4) institutional adjustment. According to Scott and Scott (2002), social adjustment is focused on three areas: (1) academic adjustment, (2) interpersonal adjustment, and (3) family adjustment.

The adjustment referred to in this study is in accordance with the concept of social adjustment of Schneider and Dan Ward (2003), which individuals do to the environment outside himself, such as home, school, and community. Adjustment according to Schneider and Dan Ward (2003), is a capacity or ability possessed by each individual to be able to react effectively, and beneficial to reality, situation, and social relations, so the criteria in social life can be fulfilled in an acceptable and satisfactory way.

Finally, from some of the conformity limitations mentioned above, it can be concluded that the definition of adjustment is a person's behavior to react to reality, situations, and social relationships to meet the needs of his life in accordance with the values or norms prevailing in the social environment. While the adaptation that is intended in this study based on the above concept is the ability of teenagers to respond to peer treatment in the education environment cause ${ }_{4}$ by the embodiment in running religious teachings, cultural values, and ethnic traditions, which can be measured through indicators such as; physical, religious, social and participation.

\section{Definition of acculturation}

Acculturation is a process of adaptation to a culture that is different from the culture owned by the individual in which the individual lives and socializes. This concept is generally used to connect the movement of individuals from their countries to other countries as they learn to live with other cultures (Ma17 moto, 2000).

It has also been defined as cultural and psychological change that occurs as a result of contact between two cultural groups or more of its in fividual members, and in general, it is usually started by immigrants who come to a State (Berry, 1990; Celano and Tyler, 1990). This is a continuous process whereby the acculturated group has unique thoughts, behaviors, and lifestyles (Berry, Kim, and Boski, 1998).

Be 7 y (1990), asserted that acculturation is divided into two groups (political organization, econo $3 y$, and social structure) and individuals (changes in behavior, values, cultural attitudes). At the group level, we can examine the national politics and stated goals of particular acculturation groups within a plural society. At the individual level, we can measure the general ideology in the dominant population or the attitude held by individuals wh19 xperience acculturation.

Acculturation is a process of cultural change that a person experiences as a result of contact between two or more with other cultures. In principle, changes occur in both cultures, but in practice, larger changes occur in minority groups, they can be measuri through faith indicators or values, attitudes, and behaviors (Berry \& Dan San, 1997). As for the purposes of this study, we will use the individual level, in the process of acculturation, where adolescents will be measured through changes in beliefs or values, attitudes, and behaviors individually at the tim 18 acculturation.

According to Ward (1996), acculturation refers to changes that occur as a result of continuous direct contact, between people of different cultural origin. At first, it concerns 
anthropology and sociology that refer to the phenomenon of the group, but finally psychology is interested in the process of acculturation of individual phenomena.

\section{Assimilation strategy}

The assimilation strategy is to let go of the cultural identity of 3 igin and choose to live with the majority culture somewhere. This can occur through the absorption of non-dominant groups into established dominant groups; or this can be by way of the unification of many groups to form a new society. In either case, sooner or later a single, relatively uniform culture develops. Assimilation occurs when people adopt local cultural values and identity 7 hile maintaining day-to-day interactions with members of the local community while rejecting or having very little interest in their home cultures.

\section{Definition of ethnic identity}

Identity is a process that leads from childhood into adulthood and bridges someone with the community around. Identity is rooted in early development and will be realized in the goals of adulthood. Erikson, argued that identity is the understanding and acceptance of self and society.

According to Mussen (1970), identity reflects a feeling of self-consistency, in which one's identity represents an integration of relatively comprehensive and consistent needs, abilities, goals, and values over time. Then, Erikson (in Archer, 1994) stated that identity demands synthesis of congenital, preferred capacity, selective identification, effective defense, successful sublimation, and consistent roles.

Marcia (in Adelson, 1980), argued that identity is a self-organizational structure, a dynamic organization of the impulses, abilities, beliefs that are structured by themselves in a person as they develop. A person will realize the uniqueness of himself and his likeness with others, if the structure itself can develop well. Then, someone will be more aware of the advantages and disadvantages that are owned by himself in interacting with the environment.

Erikson (1959), argued that in an open society, the environment provides an opportunity for individuals to be able to adjust. Identity according to Erikson (1959), occupies the concept of a normal personality development scheme. That is, that ifigtity is placed as a "concept" within the framework of psychological development in the human life cycle, so that identity can be viewed as a context of organizing the organizing theory (Ego Psychoanalytic) and shaped from experience.

According to Erikson (1968), recent and recent research indicates the need to add a domain to identity development that is rational or ethnic identity, it shows how important the issue of tribes and group members for ethnic minorities are. Erikson places particular emphasis on explaining the framework and specificity of the oppressed and exploited minority ethnicity. Phinney and Rosenthal $(1252)$, asserted that the lack of clarity and conflict related to the issue of teenage ethnicity is more common in minority groups than in the majority, and in ethnic minorities, ethnicity is a central or core is 22 of identity. Furthermore, Chun et al. (1998), stated that ethnic identity is introduced as an additional domain of ego identity that is very important for ethnic minority.

Meanwhile, the definition of ethnic identity according to Phinney (1989 13 s a complex construction that includes commitment and feelings of togetherness in a group, positive 
evaluation of the group, the interest, and knowledge of the group, and involvement in group social activities, which can be revealed through aspects of affirmation and belonging, ethnic attainment and ethnic behavior.

\section{Unexamined ethnic identity}

The defining feature here is the absence of exploration, so that if reading compulsory books at school does not show exploration, individuals at this stage will not do much to learn about their culture or ethnicity. Cosequently, the concerned youth will not talk much about it either with their parents or with their friends, and they will not look for information through reading or visiting museums, and so forth.

At this stage, the individuals may not be interested at all in their ethnicity or culture, might have never thought about it, do not see it as very important, and generally do not question it. Or the individuals may show interest and concern, perhaps perceive it as important; perhaps have a clear idea about ethnicity or their own culture, at this stage. There may even be an expression of a positive feeling or pride toward their ethnic group.

Yet they have not listened to this issue in depth; for example, they cannot discuss the advantages and disadvantages of ethnic influences on their lives. They have/have not known much about their ethnic group and their awareness about their group membership is little or minimal. The awareness of ethnic issues in their lives is superficial, perhaps obtained from parents or other family members.

\section{Ethnicity in the Search for Identity}

The defining feature is active engagement at this point, as they begin to link up with their ethnic or cultural exploration, while trying to learn more about their culture or ethnicity, and to understand their backgrounds, so as to solve problems related to meaning and implications in membership in their ethnic group, even when they have not yet indicated a clear commitment to the effort. The process of exploration may be indicated by one of the followings:

(a) Involvement in activities aimed at teaching more about their backgrounds, such as talking to others who know better, reading books, going to museums, and thinking about their backgrounds.

(b) Evidence that they have thought about ethnic issues and how they affect their lives now and in the future.

(c) Personal experiences that can increase awareness, such as experiencing discrimination (but merely mentioning that the differences between self and other ethnic groups do not show exploration).

Although teenagers are now interested and learning about their culture, yet they are in a state of confusion, they are still exploring various issues and there is no solid commitment as members to their ethnic groups. The lack of commitment is evident not only in the content of the responses but also in the color. Although the interests and knowledge of adolescents are considerable, but when interviewees show uncertainty and inconvenience with respect to their ethnic group, this means that they are still at the stage of ethnic search identity and have not achieved ethnic identity. 


\section{Achieved Ethnic Identity}

At this stage, the defining feature is that adolescents who have achieved identity are secured within themselves as members of ethnic groups, including acceptance and understanding of implications as members of the group. This acceptance and understanding are based on preventing uncertainty about ethnic issues as a result of the exploration process. While at this stage they may still continue to explore to seek a deeper understanding. However, they do not need to be deeply involved in specific ethnic activities, but they should feel comfortable as they are.

The development of ethnic identity according to Phinney (1989), as an analogy of egoyang identity occurs within the progressive timeframe of unexamined ethnic identity status, then through search to the direction of commitment and increased to achieve ethnic identity. The attainment of one's ethnic identity relates to a sense of pride in the ethnicity of the individual within his or her ethnic group. The ethnic search process is a further relationship with self esteem in adolescents reflecting the extent to which teenagers reward, value, and self-accept, as well as how much confidence teens have for the identity of a particular ethnicity.

\section{Methodology}

This research uses the qualitative method, which provides added value for identifying and exploring intangible factors such as cultural expectations, gender roles, ethnic and religious implications, and individual feelings. It explores relationships and perceptions held by affected persons and communities.

The Punjab is a community group that is identical with $\mathrm{S}_{1}$ hism. This Sikh religion was brought by Indians from Punjab (Northern India) to Medan at the end of the 19th century. To date, the people who are referred to as the Punjabi people in Medan are those who are believed to be from Punjab. However, the actual year they arrived in Medan has not been ascertained. Nevertheless, it has been observed that the Punjab people were already in Medan by the end of the nineteenth century, long before the independence of Indonesia, because Indonesia witnessed a surge in Punjab arrivals to Medan in the early 20th century, as they increased in number.

The $\mathrm{s}_{24} \mathrm{e}$ in arrival of the Punjabs to Medan is divided into 2 types. The first refers to the Punjabs who were brought to Medan by the Dutch government as plantation workers, while the second refers to the Punjabs who came as traders and as plantation workers. This can be determined because it is on record that on January 1, 1923, a Board N.V "Melk Bedrijif Sikambing" which produced cow milk for the city of Medan was established, and to supply the number of livestock that were needed in Tanjung Mulia, it became essential to enlarge their scope of operation and to increase the number of those who did the jobs. Incidentally, these jobs were carried out by the Punjabis (Sinar, 1991). As of 1930, many Punjabis had worshipped at Gurdwara (the first Temple in the village of Madras (Keling village)). An informant, Pritam Singh Dhillon (March 24, 2005) stated: "In the 1940s in the village of Anggrung, Polonia and its surroundings had settled approximately 221 Punjab family heads". Gurdip Singh Aulakh (July 27, 2005) stated: "In the early 20th century, we had already numbered hundreds and started holding associations". Thus, the above statements show that the existence of the Punjab in Indonesia did date back to a very long time. 
The Punjabis' arrival line to Medan was by sea, since they came in through Madras and Calcutta near the port of Bengal Sea, then to Penang and Belawan Port until they got to Medan. In addition to Medan they spread to Binjai, Pematang Siantar, Berastagi, and Tebing Tinggi, but some moved from India and then to Moelaboh (Aceh), and arrived in Medan.

This surge in arrival of the Punjabs to Indonesia cannot be seen as a straight forward affair, because it has gone through several stages that involved small groups. Most of them came in as unmarried singles, while others were already married before coming to Indonesia. After the end of their working period some decided to remain and get married to the natives or to their fellow Punjabs. But some went back to their own country to get married, and who later returned to Medan with their families. Kato (1982) stated in support of this observation that as the wandering movement became more popular, the returnees usually brought with them power, as well as new prestige, in addition to new ideas and practices from the outside world to their home regions.

This statement is supported by the opinion of Gurnam Singh (June 26, 2005): "The Punjab people who first came to Medan were not so many. My parents came to Medan leaving us in Punjab, after living for a while in Medan, then they came back to Punjab and took us with Medan, at the age of 8 years ". Kartar Singh Chandar (July 3, 2005) stated: "My father came in 1930 from Punjab, when he came here my father was not married. However, he settled and got married to native Javanese ethnic women".

The Punjabis who decided to immigrate to Medan from such a long distance had reasons for their immigration. Based on various analysis conducted, there were some factors that influenced the arrival of the Punjabs to Medan, namely economic, socio-cultural, political, and religious.

(a) Economic Reasons

(b) The need to improve their economic situation has been pinpointed as one of the reasons for the Punjabs' migration to Medan. This is further emphasized by the fact that majority of them refused to return to their country even after their work was over, and some of those who went back home returned invariably to settle in Medan, bringing their family members with them. It is commonplace to surmise that these Punjabs would not have found it wise to settle in Indonesia if there was nothing to gain economically. Socio-Cultural Reasons

The Punjabis who wandered also had distinctive Socio-cultural reasons for their immigration. This can be observed in the way that they have integrated with the people in the city of Medan, because as many as $90 \%$ of the population of the Punjab community in the city of Medan mix and mingle with people of different cultures/ethnicities, while the remaining $10 \%$ live in colonies with their ethnic peers.

(c) Political Reasons

In 1839, the Punjab area which was the gateway to Afghanistan and the Soviet Union where there was a Sikh kingdom was integrated to British India. So that the Punjab area which is the center of the Sikh religion became colonized by the British. When tobacco plantations developed in East Sumatra, the Netherlands lacked plantation workers. So with the help of the British, the Dutch were able to bring in a contract coolie from South India in 1874 . 


\section{(d) Religious reasons}

Every Punjab who wandered in addition to economic circumstances, also wanted to develop the Sikh religion around the world. This was done in addition to giving religious advice to each young generation of Punjabs who wandered for self-development for the sake of survival. An informant named Kirkistan Singh (June 24, 2005) argued: "After the Sikh religion develops in the Punjab region, each young generation is expected to go abroad to develop religion as well as to make improvements in education".

Sikh is t 20 name of the religious school in India. The founder and first teacher of Sikhism was Shree Guru Nanak Dev Ji, born on April 15, 1469 in Talwandi, a small village now belonging to the Pakistani territory that is located about 40 miles from the city of Lahore, now known as Nankana Sahib. Guru Nanak Dev Ji introduced this religion in 1526 AD in the Punjab region (Northern India). At the initial stage, there was no term that mentioned Guru Nanak's teachings as Sikh teachings, until the 10th teacher, Guru Gobind Singh Ji, in 1708 gathered all his followers in India and declared that their teaching was called Sikhism. Sikhism is the youngest religion in India, and it is influenced by Islam and Hinduism, which at that time constituted two major religions in India. Etymologically speaking, Sikhism means learning, in which on 6 learns about the good.

Subject variable is a term used to describe the characteristics of subjects or participants which are not manipulated such as their gender, age, socio-economic status, abilities, and personality characteristics. A distinction may be made between-subject variables, which have not been manipulated, and independent Variables, which have bee 9 manipulated. The subject of this research is the Punjabi teenager. According to The American Heritage Dictionary of th English Language, a teenager is a person between the ages of 13 and 19. Meanwhile, an adult is one who has attained maturity or legal age or who is a fully grown, matured organism.

\section{Discussion}

Based on the results of the measurement test carried out on 77 respondents in assimilation acculturation group, from the result of the analysis gathered through convergent validity it was $91_{4}$ erved that the whole item of each variable has an estimate value that is greater than 0.50 and the value of T-statistic that is greater than 1.96. This means that all items such as measure asset acculturation variables, unexamined, search, achieved, and adjusted ethnic identities are valid. Meanwhile, based on the result of construct reliability calculation on each acculturation variable of asimiasi, ethnic identity unexamined, search, achieved, and adjustment it was observed that composite reliability value is greater than 0.70 . This shows that assimilation acculturation variables, unexamined ethnic identities, search, achieved, and adjustment had very high reliability.

Furthermore, based on AVE values obtained from each asset assimilation variable, ethnic identity unexamined, search, achieved, and adjustment had AVE value that is greater than 0.50 . This shows that from each assimilation acculturation variable, ethnic identity unexamined, search, achieved, and adjustment have good convergent validity values. While the AVE root values of each assimilation acculturation variable, ethnic identity unexamined, search, achieved, and adjustment, which is greater than correlation value with other variables, is said to have good discriminant validity value. 
Based on the result of test of parameter coefficient from acculturation variable of assimilation to ethnic identity unexamined, search, and achieved, acculturation assimilation to adjustment, value of T-statistic was bigger than 1,96, hence meaning that acculturation assimilation variable is positive with significant influence to ethnic identity unexamined, search, and achieved, and against adjustment. While ethnic identity unexamined, search, danachieved to adaptation, have T-statistic value that is smaller than 1,96 . This means that every variable of ethnic identity unexamined, search, and achieved can influence positive results that is insignificant to adjustment. The results of hypothesis testing through structural model 3, the influence of acculturation assimilation mediated ethnic identity unexamined, search, danachieved to the adjustment showed a positive and insignificant influence. This relationship is illustrated in the structural model below (Figure 2):

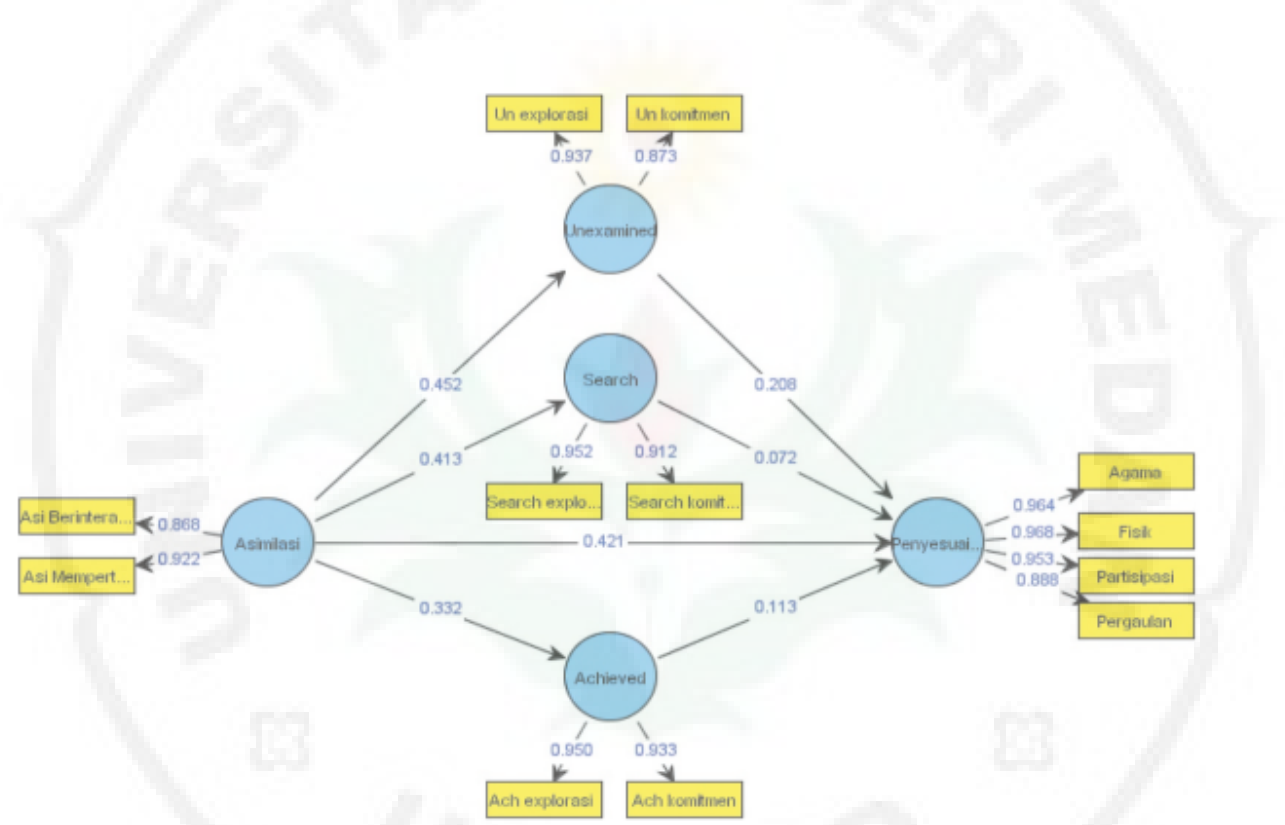

Figure 2. The model of the influence of acculturation of assimilation mediated ethnic identity unexamined, search, and achieved against adjustment.

Based on the picture above, structural model obtained results from direct and indirect influences (mediation), from viable acculturation assimilation, ethnic identity unexamined, search, achieved, and adjustment and these are shown in Table 1 as follows:

It can be observed from the table above that the direct influence of acculturation assimilation to unexamined ethnic identity is 0.452 , to search is 0.413 , and achieved against adjustment is 0.332 . The number of ethnic unexamined identity influence on adjustment is 0.208 , search for adjustments is 0.072 , and achieved against adjustment is 0.113 .

While the direct influence of acculturation assimilation gained from adjustment is 0.421 , the magnitude of acculturation effect of assimilation through ethnic identity unexamined is 0,094 , through search is 0,030 , and through achieved is 0,038 , so that acculturation effects of assimilation to adjustment through unexamined, search, and achieved are equal to 0,582 . The variables of ethnic identity mediators unexamined, search, danachieved, contribute to 
Table 1. Direct and Indirect Effect of Variable Mediation.

\begin{tabular}{|c|c|c|c|c|c|}
\hline & \multirow[b]{2}{*}{ Path Coefficient } & \multicolumn{3}{|c|}{ Indirect effect through } & \multirow[b]{2}{*}{ Total Effect } \\
\hline & & Unexamined & Search & Achieved & \\
\hline Asimilasi -> Unexamined & 0,452 & - & - & - & 0,452 \\
\hline Asimilasi -> Search & 0,413 & - & - & - & 0,413 \\
\hline Asimilasi -> Achieved & 0,332 & - & - & - & 0,332 \\
\hline Asimilasi ->Adjustment & 0,421 & 0,094 & 0,030 & 0,038 & 0,582 \\
\hline Unexamined $->$ Adjustment & 0,208 & - & - & - & 0,208 \\
\hline Search $->$ Adjustment & 0,072 & - & - & - & 0,072 \\
\hline Achieved $->$ Adjustment & 0,113 & - & - & - & 0,113 \\
\hline
\end{tabular}

make a total of 0.161 , while unexamined ethnic identity has the highest contribution to acculturation of assimilation in an attempt to shape the adjustment.

Based on the results of hypothesis 3 testing, it was observed that acculturation assimilation had a direct and positive direct effect on ethnic identity unexamined, search, and achieved. Similarly, acculturation of assimilation positively and positively affected selfadjustment, and ethnic unexamined, search, and achieved, and identified positively and insignificantly direct effects on self-adaptation. While acculturation of assimilation had an indirect effect that is positively and insignificantly carried out through ethnic unexamined identity, search, and achieved against adjustment. Thus, the result of hypothesis 3 testing shows that acculturation of assimilation mediated by ethnic unexamined, search, and achieved identity had an effect on self-adjustment, it was proven to have compatibility of theoretical model with empirical data.

Based on the structural model test 3, there is a pattern of relationships that will be described in this discussion, namely 1) the direct influence of acculturation assimilation to self-adjustment proved to have positive and significant influence, and 2) indirect effect of acculturation assimilation through ethnic identity unexamined, danachieved against adjustment with positive and insignificant effect. Here, the researcher will explain the suitability of theoretical model with empirical data between the influence of acculturation of assimilation through ethnic identity unexamined, search, danachieved to adjustment.

The direct influence of acculturation assimilation to self-adjustment has a positive and significant effect. Positive Influence means that the higher the belief of adolescents in their attitude and behavior to interact, mingle, participate with other cultures, the higher their self-adaptation to the Punjab tribe with their peers. The indicator that played a bigger role in influencing the adjustment is the physical condition, namely adolescents' physical circumstances because running traditions and religious teachings do not prevent adolescents from adjusting to peers. While the significant influence of acculturation assimilation to adjustment showed that the stronger adolescents in their beliefs, attitudes, and behaviors can interact, mingle, participate with other cultures, the stronger their adaptability with their peers. This means that adolescents who have a strong acculturation of assimilation, will have strong adaptation level to Punjab tribe with their peers, so acculturation assimilation can predict adolescents' adjustment to Punjab tribe with their peers in education environment.

The effect of acculturation of assimilation mediated by unexamined ethnic identities to conformity proved to have a positive and insignificant effect. Positive influence means that the higher adolescents have the belief, attitude, and behavior to interact, mingle, participate 
with other cultures, the better opportunity they have make good adjustment with their peers. Another indicator that played a major role in acculturation of assimilation is the exploration of the existing effort and willingness to seek information and knowledge about ethnic heritage, as this have greatly supported adolescents in adjusting to their peers. This insignificant influence means that adolescents who have acculturation of assimilation mediated by weak unexamined ethnic identity will strengthen adolescent adaptation with their peers, so that acculturation of assimilation mediated by unexamined ethnic identity can further contribute to and predict the adaptation of adolescents of Punjab tribe with their peers in the environment of education.

The influence of acculturation of assimilation mediated by ethnic identity achieved against adjustment proved to have a positive and insignificant effect. Positive influence means that the more adolescents have the belief, attitude, and behavior to interact, mingle, participate with other cultures, the better chance they have to make good adjustment with their peers. The indicator that played a major role in acculturation of assimilation is the exploration of yaitumelakukan effort and the willingness to seek information and knowledge about ethnic heritage, with a commitment to cling to the teachings of religion and ethnic tradition, but it does not prevent teenagers from being able to adapt with peers. The influence is not significant, this means that if adolescents who have acculturation of assimilation are able to mediate weakened ethnic identity, it will strengthen adolescents' adaptation with their peers, so acculturation of assimilation that is mediated by ethnic identity achieved can contribute, and predict the adaptation of adolescent community of Punjab tribe with peers in the environment of education.

Based on the results of the discussion of hypothesis 3, when we looked at the relationship between acculturation of assimilation directly with mediated ethnic identity unexamined, search and achieved, we observed positive and insignificant effect on adjustment. Acculturation of assimilation can predict self-adjustment and ethnic identity unexamined, search, and achieved as mediator to acculturation of assimilation in an effort to form adolescent adjustment of Punjab tribe with peers of educational dilingungan. When we used SEM-PLS, the results of structural model 3 analysis showed that acculturation of assimilation mediated by unexamined, search and achievement of self-adjusted ethnic identity proved to be compatible with theoretical model and with empirical data.

The results of hypothesis 3 testing showed that acculturation of assimilation mediated by ethnic identity unexamined, searches and achieved to adjustment have positive and insignificant effect on adjustment. Teenagers who have confidence, attitudes and behaviors in themselves to interact, mingle, and to participate with other cultures that are strong, when adjusting to their peers, exhibit considerable adaptability. In addition, adolescents also have an affirmation and a sense of belonging, ethnic and ethnic attitudes in themselves to seek information and knowledge about their ethnic heritage and to adhere to the teachings of their religion and ethnic tradition, can contribute to the number of adolescents' adjustment to their peers.

A teenager who has confidence, positive attitude, and good moral behavior to interact, mingle, and participate with other strong cultures, and who have not been supported by the effort and desire to seek information and knowledge of his ethnic heritage and to stick to his religious teachings and ethnic traditions, can strengthen the formation of adaptation of adolescents of Punjab tribe with peers in the education environment.The National Indonesian rules for schools require boys to have short hair, meanwhile, the Sikh people 
are obliged to have long hair and wear turbans. According to the Sikh teachings, the Sikh people must have long hair that should not be cut and must wear turban that they call Kesh.

Consequently, teenagers who have confidence, positive attitude, and good moral behavior to interact, mingle, and participate with other cultures that are strong have already begun to be supported by the effort and desire to seek information and knowledge about their ethnic heritage. However, when they cling to the teachings of religion and tradition ethically, this condition will also play a supportive role to strengthen the formation of adolescents of Punjab tribe's adjustment to their peers in the educational environment.

The direct influence of acculturation of assimilation to self-adjustment has a positive and significant effect. Positive Influence means that the more adolescents have the belief, positive attitude, and good moral behavior to interact, mingle, and participate with other cultures, the more they develop self-adaptation to their peers.

Based on the description above, it can be surmised that among the youth community of Punjab tribe in the city of Medan, acculturation is a predictor that can influence adjustment, while ethnic identity is a mediator that supports the formation of adjustment to p 15 in the educational environment. Thus, acculturation mediated by ethnic identity has played an important role in the effor ts to build adaptation with peers among the Punjab community of teenagers in the educational environment, in the city of Medan. Acculturation has showed excellent adaptability, as well as ethnic identity by playing an important role in shaping adaptation to peers in the educational environment of the Punjab youth community in Medan.

\section{Conclusion}

Acculturation of assimilation has proved to be a predictor that can influence adjustment, ethnic identity unexamined; search and achieved as a mediato ${ }_{4}$ that supports the formation of adaptation to peers in the 15 cational environment in the adolescent community of the Punjab tribe in Medan. It has played an important role in the effort to build adaptation with peers in the educational environment, and has shown the ability to adapt quite well, as well as through ethnic identity unexamined, search, and achieved as a role in shaping adaptation to peers in the educational environment of the Punjab community in the city of Medan.

\section{ORCID}

Nur'Aini (D) http://orcid.org/0000-0001-9078-1493

\section{References}

Adelson, J. (1980) Identity in Adolescence. (Ed.) Handbook of Adolescent Psychology, 159-187. New York: Wiley.

Archer, S. L. (1994). Intervention For Adolescent Identity Development. SAGE Publications, Inc. Baker, R. W., \& Siryk, B. (1984). Measuring adjustment to college. Journal of Counseling Psychology, 31, 179-189. doi:10.1037/0022-0167.31.2.179

Berry, J. W. (1990). Imposed etics, emics, and derived etics: Their conceptual and operational status in cross-cultural psychology. In T. N. Headland, K. L. Pike, \& M. Harris (Eds.). Emics and Etics: The insider/outsider debate. Newbury Park, CA: Sage. 
Berry, J. W., \& Dan San, D. L. (1997). Acculturation and Adaption. In J. W. Berry, M. H. Segall, \& C. Kagitcibasi (Eds.), Handbook of Cross Cultural Psychology, Vulume 3: Sosial Behavior and Applications. USA.

Berry, J. W., Kim, U., \& Boski, P. (1987). Psychological acculturation of immigrants. In Y. Y. Kim, \& W. B. Gudykunst (Eds.), Cross-Cultural Adaptation: Current Approaches. Newbury Park, CA: Sage.

Celano M, Tyler F. (1990). Behavioral acculturation among Vietnamese refugees in the United States. J Consult Psychol 131: 373-385.

Chun, K. M., Marin, G., \& Organista, P. B. (1998). Readings In Ethnic Psychology. Routledge.

Desmita, (2009). Psikoogi Perkembangan Peserta Didik. Bandung: PT. Rosda Krya. URL: https:// difarepositories.uin-suka.ac.id/24/1/nasri\%20malam $\% 20$ sabtu.pdf

Erikson, E. (1959). Identity and the life cycle. New York: International Universities Press.

Erikson, E. H. (1968). Identity: Youth and Crisis. NewYork: Norton. https://www.academia.edu/ 37327712/Erik_H_Erikson_Identity_Youth_and_Crisis_1_1968_W_W_Norton_and_Company_1_

Iskandar., Z. (2010). Bahan Kuliah Metode Penelitian S3. Bandung.

Kartono, K. (2008). Bimbingan anak dan remaja yang bermasalah. Jakarta: Rajawali Press.

Kato, T. (1982). Matrilinity and Migration. Ithaca: Cornell University Press.

Liliweri, A. (2009). Prasangka \& Konflik: Komunikasi Lintas Budaya Masyarakat Multikultural. PT LK is Printing Cemerlang.

Matsumoto. (2000). Culture and Psychology. Second Edition. Wadsworth, Thompson Learning.

Mussen. (1970). Handbooks of Research Metode in Child Development. Wiley Eastern Privates, Ltd.

Phinney, J. S. (1989). Stages of ethnic identity development in minority group adolescents. The Journal of Early Adolescence, 9(1-2), 34-49. https://doi.org/10.1177/0272431689091004Bandung.

Phinney, J. S., \& Rosenthal, D. A. (1992). Ethnic Identity in Adolescence: Process, Contekt and Outcome. In G. R. Adams, T. P. Gullota, \& R. Montemayor (Eds.), Adolescent Identity Formation: Advences in Adolescent Development, An Animal Book Series Volume 4. (pp. 145-172). Newbury Park, CA: Sage.

Saleh, M., Kholil, S., \& Sikumbang, A. T. (2018). Chinese ethnic communication pattern in the environment of indigenous people in Lhokseumawe, Indonesia. Budapest International Research and Critics Institute-Journal (Birci-journal), 1(4), 114-123. http://www.bircu-journal.com/index. $\mathrm{php/birci/article/view/100}$

Saman, A. 2002. Hubungan Antara Kecerdasan Emosi Dan Penyesuaian Sosial Remaja di Sekolah, (Tesis), PPs. Universitas Padjadjaran:.

Schneider, M. E., \& Dan Ward, D. J. (2003). The role of ethnic identification and perceived sosial support in Latinos adjustment to college. Hispanic Journal of Behavioral Sciences, 25(4), 539-554. November 2003. https://doi.org/10.1177/0739986303259306

Scott, R., \& Scott, W. A., (2002). Adjusment of Adolescents, Cross-cultural similarities and differences. London and New York: Routledge. DOI: https://doi.org/10.4324/9780203446010

Sinar, Tengku Luckman. (1991). Sejarah Medan Tempo Doeloe. Medan: Lembaga Penelitian dan Pengembangan Seni Budaya Melayu. https://onesearch.id/Record/IOS1. INLISM00000000017976\#details

Suharyanto, A., \& Hidayat, W. (2018). Revealing Medan's Chinese ethnic identity in advertising grief at Harian Analisa newspaper. Budapest International Research and Critics Institute-Journal (Bircijournal), 1, 83-92. https://doi.org/10.33258/birci.vli4.96

Ward, C. (1996). Acculturation. In D. Landis \& R. S. Bhagat (Eds.), Handbook of intercultural training (p. 124-147). Sage Publications, Inc. 
Effects of acculturation of assimilation in the search for cultural identity by the Punjabi ethnic minority in Medan, Indonesia

ORIGINALITY REPORT

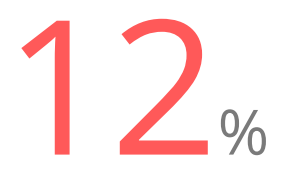

SIMILARITY INDEX

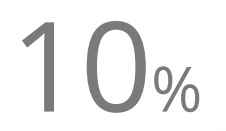

INTERNET SOURCES

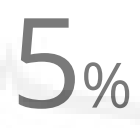

PUBLICATIONS
$6 \%$

STUDENT PAPERS

PRIMARY SOURCES

1 mafiadoc.com

2 Submitted to Universitas Pendidikan Indonesia

3 Submitted to UC, San Diego

4 ursa_majorsy.staff.gunadarma.ac.id Internet Source

5 WwW.slideshare.net

7 dspace.uta.edu

8 Submitted to Tarumanagara University 
10 www.memphis.edu

11 www.catherinecookcottone.com

12 www.satyagama.ac.id

13 link.springer.com

14 repository.uinsu.ac.id

15 uta17-kk.lib.helsinki.fi

16 James E. Marcia. "Chapter 1 The Ego Identity Status Approach to Ego Identity", Springer Science and Business Media LLC,

1993

Publication

17 citeseerx.ist.psu.edu

19 "Identity and Participation in Culturally

Diverse Societies", Wiley, 2010 
22 Jaimee Stuart, Colleen Ward. "Ethnic Identity $<1 \%$ Exploration Among South Asian Immigrant Young Adults in New Zealand", International Perspectives in Psychology, 2019 Publication

23 e-space.mmu.ac.uk 